\title{
EL VINO SANO, PORTADOR DE VIRTUDES TERAPÉUTICAS, EN EL IMAGINARIO COLECTIVO, EL DISCURSO MÉDICO Y LA MEDICINA POPULAR*
}

\author{
Por \\ XAVIER CASTRO
}

\section{RESUMEN}

Se constata un cambio en el discurso médico oficial, muy favorable en un primer momento a una amplia utilización del vino como agente terapéutico, hasta que en el transcurso del siglo XX adopta un criterio mucho más cauto. Los tradicionales «regímenes sanitarios» y los higienistas del siglo XIX encontraban virtudes positivas en el vino, en lo que concierne a la preservación de la salud. Pero tomaban en consideración las diferentes clases de vinos para determinar cuales era los más adecuados en cada caso concreto, reparando en el «temperamento» del paciente, el sexo e incluso su actividad laboral. La medicina popular ha empleado el vino como vehículo de sanación, enmarcando esta utilización en un sistema de creencias tradicionales.

\section{PALABRAS CLAVE}

Creencia, Higienistas, Medicina, Salud, Terapéutico, Vino.

* Este trabajo ha sido realizado merced a la ayuda concedida por el Ministerio de Ciencia y Tecnología al Proyecto de Investigación: «Entre la historia agraria y la historia social: producciones y consumos en Galicia (siglos XIII-XIX)» (BHA2002-03908. Septiembre del 2002) del que el autor es el Investigador Principal.

«CUADERNOS DE ESTUdIOS GALLEGOS», Tomo XLIX, Fascículo 115, Santiago 2002. 


\begin{abstract}
We notice a change in the official medical discourse, initially very favourable to use wine widely as a therapeutic agent but throughout the XX century the criteria becomes more cautious. The traditional «sanitary systems» and the higienists of the XIX century found positive virtues in wine, in relation to the preserving good health. However, they used to take into account the different types of wines in order to determine which ones were the most suitable in each specific case, according to the character, sex and even the patient's job. Popular medecine has used wine as a healing method, framing this use in a system of traditional believes.
\end{abstract}

\title{
KEYWORDS
}

Belief, Higienist, Medecine, Health, Therapeutic, Wine.

El vino era considerado no solo como un vigoroso nutriente sino también como un producto saludable. Participaban de esta creencia las «gentes del común», por supuesto, pero también la élite ilustrada. Los médicos daban también crédito a las virtualidades salutífeas del vino.

La hidalguía y las restantes capas elevadas de la sociedad gallega opinaban de este modo, como lo testimonia el juicio de un significado representante de este ambiente, don Pedro Ventura de Puga, quien califica al vino, a altura de 1830, como: «Apreciable y salutífera bebida»1.

Mencionaré algún ejemplo ilustrativo. Las órdenes religiosas se mostraban muy preocupadas en conseguir el suministro de un vino de calidad, no sólo por la no desdeñable cuestión de que sirviese de regalo al paladar, sino también, y primordialmente, por considerar que era muy ventajoso para su salud. En efecto, las religiosas do monasteiro de San Paio de Antealtares eran por esta razón muy escrupulosas en punto a la calidad del vino, que compraban generalmente en el Ribeiro y hacían

${ }^{1}$ VENTURA DE PUGA, P.: «Un plan de desarrollo para Galicia en 1832», en Boletín Auriense, Orense, 1973, p. 157.

«CUADERNOS DE ESTUDIOS GALLEGOS», Tomo XLIX, Fascículo 115, Santiago 2002. 
llevar al monasterio beneficiándose de exenciones fiscales, como el pago de la sisa, que permitía que lo obtuviesen a muy buen precio. Si consideramos que su extracción social era esencialmente hidalga, podemos razoablemente pensar que también la hidalguía participaba del criterio que expresa el clerigo en el documento que a continuación se cita. Un visitador de la orden de San Benito dejó ordenado en un libro de visita del convento de san Paio, en 1650, algo que revela la amplitud que alcanzó la idea-fuerza del vino con propiedades salutíferas; de este modo, señalaba que para que: «se ayude al regalo y mayor salud de las Sras. religiosas encargamos al P. vicario compre el vino mejor que conviniere y al traerlo por los daños que se experimentan y engaños que hacen los que lo traen venga con ello» ${ }^{2}$.

Cuesta trabajo encontrar a alguien que se apartase entonces de este denominador común en el orden de las mentalidades: constituye un hábito de vida sano ingerir vino, pero con el requisito de hacerlo con la debida moderación. Existía un paradigma de morigeración en el imaginario popular de ingesta de vino, cohonestada con el «buen sentido» del sistema de valores que inspira el refranero, tanto español, según nuestra propia constatación, como el francés, según han observado en Francia, François Loux y Philippe Richard: Sagesses du corps. La santé et la Maladie dans les proverbes français ${ }^{3}$. En consonancia con ello, un refrán recopilado en el siglo XVI recuerda: «Pan ha hartura, / y vino ha mesura» ${ }^{4}$. La prudente ingestión del vino era un paradigma firmemente inscrito en la mentalidad . popular, y era también por supuesto un firme criterio sustentado por las capas altas de la sociedad. Ello estaba en plena coincidencia con la opinión de la ciencia médica. Ya la preceptiva de la Escuela de Salerno, de honda influencia entre los médicos españoles, enfatizaba el ideal de mo-

\footnotetext{
${ }^{2}$ BURGO LÓPEZ, C.: «El consumo alimenticio del clero regular femenino en el Antíguo Régimen: El ejemplo de San Payo de Antealtares», en Studia Histórica, Vol.V., 1987, p. 233.

${ }^{3}$ LOUX, F.; RICHARD, P.: Sagesses du corps. La santé et la Maladie dans les proverbes français, G.P. Maisonneuve et Larose, Paris, 1978.

${ }^{4}$ Recopilados por el Comendador Hernán Núñez (1555) y reproducidos por Juan Sorapán de Rieros: Medicina española contenida en Proverbios vulgares de nuestra lengua. Cit. por Juan Cruz Cruz: Dietética medieval, La Val de Onsera, Huesca, 1997, p. 130, n. 125. Este refrán existe también en gallego: «Pan, con hartura, / y vino, con mesura». Refraneiro do viño, Ed. Castrelos, Vigo, 1968, p. 29.
} 
deración en la bebida: es necesario beber poco para disfrutar de salud cabal y perfecta: «Parum bibere ut recte vivas» ${ }^{5}$.

Ahora bien, las dosis que se consideraban moderadas antaño, o incluso hace cuatro décadas, no son exactamente las mismas que hogaño. En los años 60 , un manual dedicado a las amas de casa urbanas ${ }^{6}$, señalaba que tomado en pequeñas cantidades resultaba beneficioso; y la razón que invocaba hacía hincapié en el hecho de que el vino proporcionaba un gran número de calorías al cuerpo. Precisaba $\mathrm{M}^{\mathrm{a}}$ del Pilar Comín, en su «Enciclopedia del Hogar Felíz», que cada gramo de alcohol suministraba 5,6 calorías al corpo, de manera que solo resultaba nocivo cuando se tomaba en una proporción superior a un gramo por cada kilogramo de peso. Consiguientemente, una persona que pesase 65 kilogramos podía tomar diariamente, sin perjudicarse, uns 650 gramos de vino tinto corriente. Estaba bien, pues, beber algo más de medio litro diario.

Vayamos con la tesis de la medicina oficial. La Escuela de Salerno consideraba que el mejor vino engendra buenos humores ${ }^{7}$. Los médicos tenían al vino por muy sana bebida, con tal de que se hiciese un uso moderado de ella. El doctor Monlau, maestro de higienistas cuya obra ejerció una notable influencia llegando incluso a ser traducida la francés, lo consideraba de este modo ${ }^{8}$, pero con algunas cautelas y salvedades, a las que nos habremos de referir más adelante.

Ítem más: el higienismo de las postrimerías del siglo diecinueve sostenía que de todas las bebidas alcohólicas fermentadas la más sana era el vino9. El médico municipal del Ferrol y vocal de la «Junta Local de

\footnotetext{
${ }^{5}$ CIX.-Parum Bibere ut Recte Vivas. Scholae Salernitanae: De regimine sanitatis (Anglorum Regi scribit Schola Salerni). Cito por la edición de Pedro Felipe Monlau: Elementos de higiene privada ó arte de conservar la salud del individuo, Imprenta de Rivadeneyra, Madrid, 1870, p. 635.

${ }^{6}$ COMÍN, M.P.: Enciclopedia del Hogar Feliz, Editorial de Gassó Hermanos, Barcelona, 1962, p. 137.

${ }^{7}$ CV.-Melius Vinum. Scholae Salernitanae: De regimine sanitatis (Anglorum Regi scribit Schola Salerni). Cito por la edición de Pedro Felipe Monlau: op. cit., p. 634.

${ }^{8}$ MONLAU, P.F.: Elementos de Higiene privada ó arte de conservar la salud del individuo, op. cit., pp. 228-229.

${ }^{9}$ SURÓS, A.: Lecciones de higiene y economía doméstica, 1892 (Reed. Plaza y Janés, Barcelona, 1998), p. 44.
}

«CUADERNOS DE ESTUDIOS GALLEGOS», Tomo XLIX, Fascículo 115, Santiago 2002. 
Sanidad», Pastor Nieto, declaraba en un informe oficial fechado en 1894, que para el trabajador el vino era un «tónico reparador a la par que digestivo» ${ }^{10}$.

La publicación especializada en cuestiones agrícolas, Prácticas modernas», sintetizaba en 1908, los argumentos que tópicamente se solían esgrimir a la sazón, en torno a esta cuestión: «El vino, lo consideran los médicos en su aspecto higiénico como una bebida de cualidades beneficiosas. Su acción la refieren á los órganos de la digestión, al sistema nervioso, á su influencia en las grandes secreciones y á la nutrición. Ingerido en cantidades moderadas, la ligera excitación nerviosa que provoca, sobre todo en el sistema nervioso central, es altamente beneficiosa, como igualmente su influencia en las grandes secreciones, por sus efectos diuréticos y sudoríficos» ${ }^{11}$.

En una obra literaria publicada en 1888 , se recogía la prescripción de un médico que recomendaba el vino como bebida saludable, pero con la consabida moderación en la dosis: «A quien flaquear se sienta, / Dice, el doctor don José: / De vino de buena pinta / Un vasito se consienta / Que muy buen amparo es $\rangle^{12}$. Claro que esta prescripción médica -recogida por el etnógrafo Pérez Ballesteros- debía practicarse con moderación para que no sucediese lo que señalaba la siguiente estrofa de esta poesía jocosa: «¡Es una broma Jacinta / Eso del amparo ¡doy fe! / Y ¡no habrá quien me desmienta! / Pues...ya bebí...más...de treinta / Y...no...puedo tenerme e pié» ${ }^{13}$.

Al viejo espíritu de comprensión y amical confraternización con los fieles del dios Baco sobrevino después una etapa de reserva, cuando no de hostilidad manifiesta, en la que la clase médica -influída seguramente por el puritanismo calvinista de la medicina anglosajona frunció el ceño para amonestar con conveniente gravedad a los bebedores que en su criterio de entonces, jugaban irresponsablemente con la salud exponiéndose a

${ }^{10}$ NIETO RODRÍGUEZ, P.: Memoria acerca de las condiciones higiénicas y estado sanitario de El Ferrol, Imprenta de El Departamento, El Ferrol, 1895, p. 18.

${ }^{11}$ M. S. T. : "La campaña de La Cierva. Su importancia para los vinicultores. I», Prácticas modernas é industrias rurales, Año VI, La Coruña, 1 de noviembre de 1908, p. 332.

${ }^{12}$ PÉREZ BALLESTEROS, J.: «O Bebedor», Foguetes, Andrés Martínez, editor, A Cruña, 1888 , p. 81.

${ }^{13}$ PÉREZ BALLESTEROS, J.: «O Bebedor», op. cit., p. 82. 
contraer graves dolencias, cardíacas, hepáticas y algunas otras más. Sin embargo, desde hace unos pocos años, parece haberse modificado un tanto este intransigente criterio. Con un sentido más ponderado de la cuestión, la indulgencia médica llega hasta considerar casi recomendable tomar un vasito diario de vino tinto con la comida, para disipar el estrés y activar el sistema circulatorio, por ejemplo.

Se tenía por especialmente sano el vino elaborado en la bodega propia, con uvas suyas. A. Vicenti, en sus «Perfiles gallegos», empleaba el adjetivo «saludable» ${ }^{14}$ para calificar al vino «de la casa» que se elaboraba, cumpliendo estos requisitos, en la comarca de A Ulla, en la que había dado en ir a parar.

Xosé Posada estima que el agricultor gallego no cultivaba ningún otro producto con tanto cariño como sus viñas. El vino que elabora él mismo en su lagar y con sus propias uvas, tenía que ser el mejor del mundo. Era un producto sin mediaciones, el espíritu de la casa de labranza, el jugo de la tierra en toda su pureza ${ }^{15}$. ¿Cómo no habría de considerarlo sano?

Desde luego, los campesinos parece que se esforzaban más en hacer mejor vino, menos adulterado $\mathrm{y}$, por tanto, más sano, cuando se destinaba al consumo doméstico. De hecho, Posada advirtió que los viñateros que elaboraban el vino fundamentalmente para ellos y sus familias lo «sacaban» mejor que cuando lo hacían sobre todo para vender ${ }^{16}$. Y esto no es contradictorio, aunque a primera vista podría parecerlo, con el hecho de que en general los viticultores que vivían en mucha o buena parte de la venta de su vino, debieran reservar el mejor de la cosecha para el mercado, por ser el que más pingüe benefició permitía obtener, y quedarse con el más corriente para el consumo casero.

Ahora bien, en relación con el vino de la casa cabe hacer alguna matización. El paisano consideraba que el vino era especialmente sano si se elaboraba con todo escrúpulo y sin añadirle «química». Solían decir: «es

${ }^{14}$ VICENTI, A.: A orillas del Ulla (Perfiles gallegos), en J. A. Durán: Aldeas, aldeanos y labriegos en la Galicia tradicional, Instituto de Estudios Agrarios, Pesqueros y Alimentarios (Ministerio de Agricultura, Pesca y Alimentación), Madrid, 1984, pp. 43-44.

${ }^{15}$ POSADA, X.: Os viños de Galicia, Diputación Provincial de Orense, Orense, 1978 , p. 15.

${ }^{16}$ POSADA, X.: Os viños de Galicia, op. cit., p. 84. 
natural de la uva, nosotros no le echamos nada ${ }^{17}$. Es bien conocido un refrán que proclama que: «No hay mejor vino que el de la viña» ${ }^{18}$.

Cierto es que los técnicos y connaisseurs en vinos sostienen que tal cosa es un mito, puesto que la fermentación y el proceso general de la vinificación es en sí mismo considerado un conjunto de reacciones físico-químicas, y que el problema no reside tanto en el recurso o no al arsenal de recursos de la química y procedimientos enológicos, que se tiene por indispensable, como en el acierto en las cantidades y la pericia en el manejo y gobierno de los procesos. Pero la opinión popular ha venido siendo obstinadamente dispareja: idealiza lo «natural» y execra «lo que tiene química», y no digamos ya si tiene «mucha química».

Existe el orgullo de hacer un producto casero, natural y sano. En la parroquia estradense de Couso, en la década de 1940, la gente se sentía muy satisfecha por hacer el vino «natural de todo», puesto que no le echaban metabisulfito ni ninguna otra cosa ${ }^{19}$. También un bodeguero, de Cela (Bueu), Celso Estévez, se jactaba de hacer un vino completamente natural. Influía mucho en él el prestigio que tenía hacer el vino sin química y la dificultad práctica en que se encontraba para determinar las dosis correctas que convenía echarle de ese producto. En el valle de Cela, donde se elaboran caldos de tradición artesanal y el vino que se comercializa, casi exclusivamente en la zona, se embotellaba sin etiqueta, el cosechero que le añadía bisulfito tenía buen cuidado de no decirlo, porque se solía considerar como algo impropio ${ }^{20}$. Pensaban que incurrían en una suerte de deshonestidad los que le «echaban el producto». Equivalía casi, o sin casi, a hacer trampa.

También ciertas élites minoritarias, con ideología marcada por recia fibra casticista, cultivaban una suerte de mitificación casticista («enxe-

\footnotetext{
${ }^{17}$ Expresión popular que ha sido recogida en: Xosé Posada: Os viños de Galicia, Diputación Provincial de Orense, Orense, 1978, p. 15.

${ }^{18}$ FERRO RUIBAL, X.: Refraneiro galego básico, Galaxia (Biblioteca Básica), Vigo, 1987, p. 595.

${ }^{19}$ Entrevista realizada por Xavier Castro Pérez a José Ribeira, a su mujer Fina Varela y a su hermana Jesusa, residentes en Couso (Concello de A Estrada). Todos ellos nacieron alrededor del 1930.

${ }^{20}$ Entrevista realizada por Xavier Castro Pérez a Celso Estévez, albañil-constructor e pequeno bodegueiro. Residente en Cela (Bueu).
}

«CUADERNOS DE ESTUDIOS GALLEGOS», Tomo XLIX, Fascículo 115, Santiago 2002. 
brista») que daba en enaltecer la pureza del «vino de la tierra» frente a la manipulación farmacológica. En la pieza teatral «A Lagarada», Otero Pedrayo le hace decir a «una pipa de roble» (porque eso es capaz de hacer la magia literaria de este autor), con tono minusvaloratorio que: «En la actualidad el bisulfito impera por las bodegas ${ }^{21}$ de la comarca del Ribeiro.

Existían también discrepancias sobre lo que se debía entender como vino natural. A comienzos del siglo XX estaba muy arraigada en el seno del pueblo la creencia en que los vinos corregidos, «es decir, los que no están exclusivamente preparados con $u v a »^{22}$, resultaban perjudiciales para la salud. Ahora bien, el director del Laboratorio Municipal de Ourense aducía que esto era una suposición errónea puesto que los vinos para su elaboración y crianza requerían alguna enmienda ${ }^{23}$.

Por otra parte, el vino de la casa era conocido y por lo tanto fiable. No se puede decir otro tanto acerca del que se adquiría, que generalmente se comercializaba a granel. Tradicionalmente la adulteración del vino traficado en España alcanzó cotas extremadamente elevadas, como se puede apreciar en la investigación realizada por Pan-Montojo ${ }^{24}$, o en las respuestas al cuestionario de la «Crisis agrícola y pecuaria»" ${ }^{25}$, publicado en 1887. Beber tales vinos constituía un riesgo serio para la salud. Lo advertía en 1838 un informe da Sociedad Económica de Amigos del País, radicada en Santiago, que daba cuenta de las adulteraciones que se cometían con el vino del Ribeiro, y consideraba que tales manipulaciones resultaban nocivas para el consumidor. Estaban tan geralizadas que la docta institución recomendaba a las persoas que quisieran preservar su salud recurrir al vino de cosecha propia ${ }^{26}$.

${ }^{21}$ OTERO PEDRAYO, R.: A Lagarada, Galaxia, Vigo, 1998, p. 72.

${ }^{22}$ FERNÁNDEZ MARTÍNEZ, J.: Prácticas vinícolas, Imprenta y Papelería de «La Región», Orense, 1913, p. 38.

${ }^{23}$ FERNÁNDEZ MARTÍNEZ, J.: Prácticas vinicolas, op. cit., pp. 38-39.

${ }^{24}$ PAN-MONTOJO, J.: La bodega del mundo. La vid y el vino en España (18001936), Alianza Universidad, Madrid, 1994.

${ }^{25}$ La crisis agrícola y pecuaria (Publicación Oficial), Establecimiento Tipográfico «Sucesores de Rivadeneyra» Impresores de la Casa Real, Madrid, 1887.

${ }^{26}$ Informe dado por la Sociedad Económica de Amigos del País de la Ciudad de Santiago, sobre el modo y medios que pueden emplearse para promover y elevar al grado de que es susceptible la industria agricolo-mercantil de los Vinos y Aguardientes, Imprenta de la V. é H. de Compañél, Santiago, 1838, p. 10.

«CUADERNOS DE ESTUDIOS GALLEGOS», Tomo XLIX, Fascículo 115, Santiago 2002. 
El médico Monlau hacía la siguiente observación al promediar el siglo XIX: «El vino puro y natural es, puede decirse, un artículo raro: ¡tanta es, y tan generalizada está, la codicia de los especuladores para falsificarlo» ${ }^{27}$.

En la literatura vemos reflejada la estela de este problema. Un hidalgo perfilado literariamente por Otero Pedrayo, de precaria salud, abandonó su residencia en la costa «por no sentar bien a mi pobre cuerpo el vino de los maragatos ${ }^{28}$. Se resolvió a trasladarse así a una parroquia del Ribeiro, donde podía tomar con todas las garantías el que allí se producía, ya que el que se comercializaba no le inspiraba confianza.

Se tenía por tan saludable al vino casero que ni siquiera se le consideraba virtualmente capaz de provocar «borrascas»; es decir, esas leves contrariedades para el cuerpo que representan las borracheras. Todavía recientemente el psiquiatra Emilio Gonzalez se hizo eco de la costumbre de los paisanos de considerar que su vino, el que ellos hacían, non podía sentar mal: «Es de casa, no hace daño», acostumbraban a decir algunos de sus pacientes. Ni siquiera se admitía que puediese provocar el daño de menor porte, si no se auto-infligía con mucha frecuencia, de causar el extravío transitorio de la razón. En efecto, se pensaba que: «Nadie se emborracha con el vino de su casa» ${ }^{29}$, como tajantemente negaba un proverbio popular. Verdad es que esos vinos solían tener pocos grados, pero no lo es menos -y en ello no se solía reparar- que a base de porfiar e insistir en el trago...

No solo acontecía en España que el vino fuese una bebida frecuentemente más saludable que el agua. $\mathrm{O}$ que cuando menos se la tuviese por tal. A mediados del siglo XIX, en Francia, el vino aparecía como un complemento sano, en la medida en que venía a reforzar un régimen alimenticio deficiente y también porque reemplazaba al agua polucionada que la mayoría de la gente estaba obligada a beber ${ }^{30}$. Constituye un hecho esca-

${ }^{27}$ FELIPE MONLAU, P.: Elementos de Higiene privada ó arte de conservar la salud del individuo, op. cit., p. 232.

${ }^{28}$ OTERO PEDRAYO, R.: A Lagarada, op. cit., p. 88.

${ }^{29}$ Refraneiro do viño, op. cit., p. 39.

${ }^{30}$ WEBER, E.: La fin des terroirs. La modernisation de la France rurale 1870-1914, Fayard, France, 1983, p. 220.

«CUADERNOS DE ESTUDIOS GALLEGOS», Tomo XLIX, Fascículo 115, Santiago 2002. 
samente difundido que existía una contaminación importante que afectaba a las aguas potables ya antes de la era industrial. Y no digamos ya al adentrarnos en ella. El vino parecía no ser tan peligroso como el agua.

En España, una geografía médica, un poco anterior a 1917, señalaba un aspecto que se puede generalizar a buena parte del conjunto de las aglomeraciones rurales del país: «los muladares y estercoleros, se establecen en las inmediaciones del poblado» ${ }^{31}$. En algunas granjas incluso se acumulaban tales inmundicias a la vera de las casas que ocasionaban infiltraciones que afectaban a los pozos de agua. Además no se cuidaban las aguas potables para evitar contaminaciones «y en los tiempos lluviosos hácese imposible su uso» ${ }^{32}$.

La situación de las fuentes públicas distaba de ser satisfactoria en términos generales. Una forma de contaminación que les afectaba en las ciudades y villas era la que se producía como consecuencia del lavado de muebles y ropa en ellas (incluída la de los enfermos contagiosos). Ordenanzas y bandos de Policía Urbana ${ }^{33}$ tuvieron que reiterar la prohibición de esta practica como también la de arrojar en las fuentes el polvo de las viviendas.

Aparecen reverberaciones de estos fenómenos en diversas manifestaciones de la cultura popular. Un cantar del ayuntamiento de Trabada, todavía vivo en las últimas décadas, aportado por un informante que lo recordaba par coeur, expresaba lo siguiente:

«Agua pura de la fuente madre de ranas y sapos, donde vos lavais los trapos ¿quereis que la beba yo? -No.

Vino puro y a menudo de ese que beben los reyes, el auga para los bueyes que tienen el cuello duro» ${ }^{34}$.

\footnotetext{
${ }^{31}$ Apuntes para una geografia médica de Villamantilla. Villa de la provincia de Madrid, 1917. RANM, de Madrid, s.p.

${ }^{32}$ Apuntes para una geografia médica de Villamantilla. Villa de la provincia de Madrid, op. cit.

${ }^{33}$ AHUS. Ordenanzas de Policía Urbana 1780-1900, passim.

${ }^{34}$ Copla aportada por José Ramón Loureiro.
} 
También una copla de la comarca de la Limia Baixa, anotada con anterioridad a 1932, proclamaba lo siguiente:

«Dadme vino, dadme vino, que agua no puedo beber; cayó un bicho en la fuente, tengo miedo de morir» ${ }^{35}$.

En la prensa y en la literatura también se encuentran ecos referidos a esta cuestión. El autor del artículo publicado en un periódico de 1876 (probablemente Lamas Carvajal), comentaba refiriéndose a la ciudad de Ourense, que en cierta ocasión quiso tomar un neto de vino, pero su cuba estaba vacía, «y tuve que beber agua, de la fuente de la Plaza do Ferro, que a fe mía viene muy sucia» ${ }^{36}$. Marcial Valladares en su obra: «Maxina o la hija espúrea» («Maxina ou a filla espúrea») presenta dos mujeres de viso en la romería del Pico Sacro, que se celebraba el 27 de maio de 1866. Se encuentran con dos peregrinos que les piden prestado un vaso para beber en la fuente que allí había. Una de ellas les advierte que: «-Quizá que haga daño el agua (...) Vino será mejor y hay también aquí». Y en razón partida de higiene y cortesía, la dama les ofrece gentilmente vino: «QQuiere el señor probarle? ¿Quieren probarle entrambos?» ${ }^{37}$.

Mencionaremos dos testimonios más que abundan en la extendida consideración del vino como bebida más higiénica que el agua, conforme lo expresa un proverbio, del que hay noticia de que ha sido recopilado en el siglo XIX: «Vino sine aqua, corpore triaca; aqua sine vino, corpore venino ${ }^{38}$. En latín macarrónico el refrán parece dar a entender que el vino puro es un gran remedio. En cambio el agua sin sanear con vino, es un veneno. Monlau lo da por atinado. Por lo demás, fuere pretexto para

${ }^{35}$ LORENZO FERNÁNDEZ, X.: Cantigueiro popular da Limia Baixa, Editorial Galaxia, Vigo, 1973, cantiga 694, p. 66.

${ }^{36}$ "Os Meus Compañeiros de Monteira», O Tio Marcos d'a Portela. Parrafeos c'o pobo gallego, Ano Primeiro. Parrafeo Trece. Ourense, 22 de Agosto de 1876, p. 50

${ }^{37}$ VALLADARES NÚÑEZ, M.: Maxina ou a filla espúrea, Galaxia, 1970, p. 116

${ }^{38}$ FELIPE MONLAU, P.: «La higiene en los refranes castellanos». Apéndice II. In Elementos de higiene privada ó arte de conservar la salud del individuo, Imprenta de Rivadeneyra, Madrid, 1870, p. 676.

«CUADERNOS DE ESTUDIOS GALLEGOS», Tomo XLIX, Fascículo 115, Santiago 2002. 
beber vino genuino o fuese quizás un temor justificado, señalaba un refrán consignado en el siglo XIX: «No me echeis agua en el vino, que andan guzarapas por el rio» ${ }^{39}$.

El primero de los testimonios proviene del relato del Proto-Médico encargado de investigar una epidemia de fiebre tifoidea que se declaró en la ciudad de Vigo y sus aledaños, en el año 1793. Su informe revela que imposibilitada la gente del sólito recurso del vino, calificado como «digestivo antipútrido» que obraría como barrera frente a las infestaciones, hubo de recurrir al agua contaminada. En efecto, en la época anterior a la proclamación de la epidemia le faltó a los habitantes de la localidad: «(...) el digestivo antipútrido, por lo que usaron más de sus aguas impregnadas de la expresada podredumbre $»^{40}$.

El segundo hecho se sitúa hacia el ecuador del siglo XX. En efecto, hacia el año 1950 estaban prohibidas por el reglamento del Seminario de Santiago de Compostela las bebidas alcohólicas en las comidas. Los seminaristas -muchos de ellos de proveniencia campesina y habituados a servirse de la bebida fermentada- reclamaban sin éxito que se sirviese vino a la hora de comer y de cenar. Pero un buen día vieron el cielo abierto. La oportunidad vino dada con ocasión de una indigestión padecida por un seminarista, cuando el médico que efectuó el reconocimiento, el doctor Daviña -según le parece recordar al informante que fue testigo del suceso- observó que la indisposición había sido provocada por beber agua en vez de vino. A la vista de lo cual, el rector del seminario, que se apellidaba Capón, decidió que en adelante se sirviese vino en la hora de la comida, al parecer blanco, con excepción de los viernes de Cuaresma ${ }^{41}$.

Llegados a este punto es, pues, de saber que la ciencia médica -en concertado compás con el criterio popular, en muchos casos- tomaba en consideración cierto número de factores para conceptualizar como saludable el vino, además de los ya referidos atinentes a la indispensable cualidad de su pureza y a la inexorable parquedad en su ingesta.

\footnotetext{
${ }^{39}$ FELIPE MONLAU, P.: «La higiene en los refranes castellanos», op. cit., p. 676.

${ }^{40}$ MEIJIDE PARDO, A.: «Noticia de un brote epidémico ocurrido en la comarca viguesa en 1793», Medicina Galaica, nº. 22, Julio-Septiembre, 1983, p. 6.

${ }^{41}$ Entrevista realizada por Xavier Castro a Xosé Ramón Barreiro Fernández, catedrático de Historia Contemporánea y en la actualidad presidente de la Real Academia Galega.
} 
Complementariamente a lo ya apuntado sobre la requerida depuración inmaculada se tenía por conveniente que, como precisaba el higienista Monlau, «Toda mezcla de vinos es, por regla general, anti-higiénica». La única combinación que no le merecía apenas reparos era la de los vinos muy alcohólicos con los flacos o ligeros ${ }^{42}$.

Tampoco veían mal los higienistas la amalgama de vino y agua; incluso lo tenían por más higiénico. A mi entender, no era este un criterio compartido por los aficionados al vino ni por la opinión popular en general. Pero los médicos del siglo XIX parecían tenerlo muy claro; Monlau señalaba que: «El vino puro apaga mal la sed, ó la apaga por poco tiempo; pero mezclado con mucho agua la apaga bien, y es á la par un buen disolvente de los alimentos $»^{43}$. Por cierto, que la Escuela de Salerno consideraba que el vino aguado era necesario dejar que se mezclara bien, porque bebido demasiado pronto, podía engendrar la lepra ${ }^{44}$.

Por lo demás, para que el vino se considerase sano debería cumplir ciertos resquisitos intrínsecos y poseer determinadas cualidades organolépticas. En primer lugar se apreciaba su claridad y limpieza, cuestión obviamente muy relacionada con la preocupación por la pureza del mosto. Arnaldo de Vilanova, en su «Regimen Sanitatis» (c. 1470), preconizaba que el vino, «en su calidad, sea claro y delicado» ${ }^{45}$.

Atendiendo a la densidad y transparencia del vino, Monlau pensaba que los mostos claros y limpios eran preferibles a los turbios o espesos, por considerar que contienen en general muchas impurezas y son de digestión laboriosa ${ }^{46}$. Tropezaba esta visión con la extendida creencia po-

${ }^{42}$ FELIPE MONLAU, P.: Elementos de Higiene privada ó arte de conservar la salud del individuo, op. cit., p. 236.

${ }^{43}$ FELIPE MONLAU, P.: Elementos de Higiene privada ó arte de conservar la salud del individuo, op. cit., p. 237.

${ }^{44}$ CVII.-Vina Varia. Scholae Salernitanae: De regimine sanitatis (Anglorum Regi scribit Schola Salerni). Cito por la edición de Pedro Felipe Monlau: op. cit, p. 635.

${ }^{45}$ VILANOVA, A. de: Regimen Sanitatis, c. 1470. Versión publicada por Jerónimo de Mondragón en 1606, con el título: Maravilloso regimiento y orden de vivir, actualizada ortograficamente y anotada por Juan Cruz Cruz: Régimen de Salud. Apéndice de Dietética medieval, La Val de Onsera, Huesca, 1997, p. 308.

${ }^{46}$ FELIPE MONLAU, P.: Elementos de Higiene privada ó arte de conservar la salud del individuo, op. cit., p. 234.

«CUADERNOS DE ESTUDIOS GALLEGOS», Tomo XLIX, Fascículo 115, Santiago 2002. 
pular en que los mejores y más nutritivos vinos -tintos en especial- eran aquellos bien espesos y densos.

El color era otro aspecto relevante. En efecto, la Escuela de Salerno, que comenzó a darse a conocer a partir del siglo $\mathrm{X}$, consideraba que el vino blanco es suave y nutritivo ${ }^{47}$. En lo concerniente al vino tinto (vinum rubeum), sostenía que bebido con algún exceso, constriñe el vientre y pone la voz ronca ${ }^{48}$. Y aún discernía el vino entre el vinum rubens, rojo, y el niger, o negro. Del vino niger decía que embriagaba con más rapidez ${ }^{49}$, provoca estreñimiento de vientre, irrita y daña las entrañas ${ }^{50}$. Y además, «empereza» el cuerpo ${ }^{51}$, lo que viene a significar que le produce un efecto de torpor.

En la centuria decimonónica se pensaba que el vino tinto era menos digerible que el blanco. Así, el doctor Monlau, consideraba en el siglo XIX que los vinos blancos y claretes resultaban por lo general más digeribles que los tintos ${ }^{52}$. Y su acción resultaba además más excitante, en el sentido de que contribuían además a activar la digestión de los alimentos. Esto se debería a que al tener los vinos blancos mayor graduación alcohólica excitarían, término que parece ser empleado en el sentido de activarían, más facilmente la función digestiva del estómago. De este modo, según Monlau, los vinos amarillos o pajizos, y secos, se empleaban por esta cualidad excitante, como condimentos «para solicitar la accion del estómago ${ }^{53}$. Y sin dejarse llevar por mentalidad chauvinista alguna, anota, que los menos excitantes de todos son los del

${ }^{47}$ CVII.-Vina Varia. Scholae Salernitanae: De regimine sanitatis (Anglorum Regi scribit Schola Salerni). Cito por la edición de Pedro Felipe Monlau: op. cit., p. 634.

${ }^{48}$ CVII.-Vina Varia. Scholae Salernitanae: De regimine sanitatis (Anglorum Regi scribit Schola Salerni). Cito por la edición de Pedro Felipe Monlau: op. cit., p. 635.

${ }^{49}$ CIV.-Vini Novi Efectus. Scholae Salernitanae: De regimine sanitatis (Anglorum Regi scribit Schola Salerni). Cito por la edición de Pedro Felipe Monlau: op. cit., p. 634.

${ }^{50}$ CIV.-Vini Novi Efectus. Scholae Salernitanae: De regimine sanitatis (Anglorum Regi scribit Schola Salerni). Cito por la edición de Pedro Felipe Monlau: op. cit., p. 634.

${ }^{51}$ CV.-Melius Vinum. Scholae Salernitanae: De regimine sanitatis (Anglorum Regi scribit Schola Salerni). Cito por la edición de Pedro Felipe Monlau: op. cit., p. 634.

${ }^{52}$ FELIPE MONLAU, P.: Elementos de Higiene privada ó arte de conservar la salud del individuo, op. cit., p. 233.

${ }^{53}$ FELIPE MONLAU, P.: Elementos de Higiene privada ó arte de conservar la salud del individuo, op. cit., p. 233.

«CUADERNOS DE ESTUDIOS GALLEGOS», Tomo XLIX, Fascículo 115, Santiago 2002. 
Rhin y Burdeos. Según él, estos vinos no embriagan sino tomados en dosis muy considerables. Son, entre los secos, los que mejor convienen a las personas irritables ${ }^{54}$.

Vemos repetido este argumento en un tratado popular de medicina de la década de 1930, redactado por un cuerpo de reputados médicos e higienistas, bajo la dirección del doctor Saimbraum, señalaba que el vino blanco era más excitante que el tinto por tener mayor riqueza alcohólica ${ }^{55}$.

Pero la acción excitante de los vinos blancos no convenía a todas las personas. Una profesora de la Escuela de Magisterio de Pontevedra, se hacía eco en 1929, de la consideración de los vinos blancos, más abundantes por lo común que los tintos, en tartrato, ácido de potasio y calcio, como perjudiciales para los dispépticos ${ }^{56}$, es decir para las personas que padecían la enfermedad crónica caracterizada por la digestión laboriosa e imperfecta.

A los vinos tintos y blancos se les atribuían asimismo otras cualidades diferenciales en lo que a la salud se refiere. El tratado del doctor Saimbraum, señalaba que los vinos tintos predisponen al estreñimiento, en tanto que los blancos, más ácidos, «provocan más bien la diarrea» ${ }^{57}$. En lo que concierne a los vinos tintos, era el tanino el agente que comunicaba a los vino su estipticidad y aspereza, actuando -se decía- como una potencia astringente ${ }^{58}$.

En la cualidad del sabor no se insistía tanto. Quizá porque la Escuela de Salerno no concedía importancia al sabor a la hora de apreciar un potu fermentado, a no ser que entendamos como tal el requisito de «frigida»,

${ }^{54}$ FELIPE MONLAU, P.: Elementos de Higiene privada ó arte de conservar la salud del individuo, op. cit., p. 233.

${ }^{55}$ DOCTOR SAIMBRAUM: Tratado popular de medicina, Ediciones Hymsa, Barcelona, s. a. (1935), p. 160.

${ }^{56}$ SAZ Y ÁLVAREZ, F.R.: Apuntes de economía doméstica para uso de las Escuelas Normales, Imprenta de Celestino Peón Villar, $2^{\circ}$ edic., Pontevedra, 1929, p. 186

${ }^{57}$ DOCTOR SAIMBRAUM: Tratado popular de medicina, op. cit., p. 160.

${ }^{58}$ GINÉ Y PARTAGÁS, J.: Curso elemental de higiene privada y pública, Tomo Primero, Higiene Privada, $2^{\mathrm{a}}$ ed., Barcelona, Imprenta de Narciso Ramirez y Compañia, Barcelona, 1871, pp. 221-222.

«CUADERNOS DE ESTUDIOS GALLEGOS», Tomo XLIX, Fascículo 115, Santiago 2002. 
que Monlau traduce como «fresco $»^{59}$. Vilanova se inclinaba por el vino de sabor «sencillo y puro ${ }^{60}$.

Mayor énfasis se ponía en el requisito de la edad de vino. La Escuela de Salerno consideraba que el vino nuevo da mayor calor al pecho, es diurético y se sube pronto a la cabeza ${ }^{61}$. Monlau sostenía que la distinta edad del vino ejercía de distinta manera sobre la salud. El vino nuevo le parecía ingrato al paladar, de digestión penosa, «y causa acedías e irritaciones gastro-intestinales». En su opinión, «El vino higiénicamente potable debe tener por lo menos un año ${ }^{62}$. Precisando más esto, señalaba que: De un modo general, «Los vinos de uno o dos años, claros, ligeros y poco alcohólicos, son los verdaderos vinos usuales, ó los que deber ser preferidos para el uso habitual, pero siempre mesurado» ${ }^{63}$.

Particularmente nocivos y detestables parecían a los médicos y a las autoridades municipales (encargadas de la supervisión y control de los vinos en el ámbito territorial del ayuntamiento) los vinos verdes o inmaduros. El representante más cualificado del higienismo español señalaba que: «Los vinos hechos con uvas inmaturas (vinos verdes) son ásperos, acerbos, carecen de perfume, y son tan malsanos como los vinos nuevos o recién preparados $\rangle^{64}$. Daba también Monlau una receta para mejorarlos: «La aspereza del vino puede obviarse dejando evaporar el zumo de la uva, si es demaisado acuoso, y echando en él un poco de azúcar en bruto para reemplazar la materia sacarina que falta» ${ }^{65}$.

Monlau y los restantes higienistas tenían por saludables a los vinos añejos, siempre que estuviesen bien elaborados. Sostenía, en efecto, este autor que los vinos añejos o bien rancios, eran más claros, «más sápidos y

${ }^{59}$ CII.-Vini Probatio. Scholae Salernitanae: De regimine sanitatis (Anglorum Regi scribit Schola Salerni). Cito por la edición de Pedro Felipe Monlau: op. cit., p. 633.

${ }^{60}$ VILANOVA, A. de: Regimen Sanitatis, c. 1470. Op. cit., p. 308.

${ }^{61}$ CIV.-Vini Novi Efectus. Scholae Salernitanae: De regimine sanitatis (Anglorum Regi scribit Schola Salerni). Cito por la edición de Pedro Felipe Monlau: op. cit., p. 634.

${ }^{62}$ FELIPE MONLAU, P.: Elementos de Higiene privada ó arte de conservar la salud del individuo, op. cit., p. 234.

${ }^{63}$ FELIPE MONLAU, P.: Elementos de Higiene privada ó arte de conservar la salud del individuo, op. cit., p. 237.

${ }^{64}$ FELIPE MONLAU, P.: Elementos de Higiene privada ó arte de conservar la salud del individuo, op. cit., p. 234.

${ }^{65}$ FELIPE MONLAU, P.: Elementos de Higiene privada ó arte de conservar la salud del individuo, op. cit., p. 234.

«CUADERNOS DE ESTUDIOS GALLEGOS», Tomo XLIX, Fascículo 115, Santiago 2002. 
más digeribles, más perfumados, y por todo estilo superiores á los nuevos $\rangle^{66}$. Aunque se encarecía suma moderación en su uso. Tenían también otra ventaja: la embriaguez ocasionada por la ingesta excesiva de vinos añejos no va tan frecuentemente acompañada de indigestión, como sucede con la producían los nuevos ${ }^{67}$.

Importaba mucho también el nivel de acidez que tuviesen. En efecto, los vinos ácidos eran criticados por los higienistas, por entender que esta clase de vinos, «naturalmente ácidos o agrillos», como el chacolí y otros, son picantes y «muchas veces» producen cólicos, particularmente a las personas que no están acostumbradas a su uso. Entèndía Monlau que la Autoridad debía prohibir severamente la expedición de los vinos acedados ${ }^{68}$.

El higienista Juan Giné y Partagás, en su obra «Curso elemental de higiene privada y pública», (publicada en 1871) indicaba que el ácido acético puede neutralizar los álcalis del tubo digestivo que son indispensables para la elaboración de los elementos: de ahí que los vinos ácidos fuesen perniciosos, puesto que causaban irritaciones gastro-intestinales y dispépsias ${ }^{69}$.

No se desatendía tampoco la cuestión del nivel de azúcar, según el cual se agrupaban los vinos en dulces o secos.

El «Regimen Sanitatis», de la Escuela napolitana de Salerno ${ }^{70}$, que recogió la tradición anterior de la medicina y tuvo una perdurable inflencia posterior, señala que «Los mostos dulces y suaves mueven la orina, inflan y sueltan el vientre», en tanto que los secos y austeros suprimen la orina, provocan flato, y además obstruyen el hígado y engendran concreciones y cálculos ${ }^{71}$.

${ }^{66}$ FELIPE MONLAU, P.: Elementos de Higiene privada ó arte de conservar la salud del individuo, op. cit., p. 235.

${ }^{67}$ FELIPE MONLAU, P.: Elementos de Higiene privada ó arte de conservar la salud del individuo, op. cit., p. 235.

${ }^{68}$ FELIPE MONLAU, P.: Elementos de Higiene privada ó arte de conservar la salud del individuo, op. cit., p. 234.

${ }^{69}$ GINÉ Y PARTAGÁS, J.: Curso elemental de higiene privada y pública, op. cit., pp. 221-222.

${ }^{70}$ KRISTELLER, O. P.: Studi sulla scuola medica salernitana, Napoli, 1986.

${ }^{71}$ CIII.-Mustum. Scholae Salernitanae: De regimine sanitatis (Anglorum Regi scribit Schola Salerni). Cito por la edición de Pedro Felipe Monlau: op. cit., p. 634.

«CUADERNOS DE ESTUDIOS GALLEGOS», Tomo XLIX, Fascículo 115, Santiago 2002. 
En opinión de un médico en 1839, Ignacio Pusalgas, autor de «Compendio de higiene», los vinos dulces de España (como también los de este tipo de Francia, Italia, Grecia, Hungría, etc.) cuando estaban «bien fermentados y nada sofisticados» convenían mucho a los convalecientes y personas de débil constitución. Debían tomarse en parca dosis y de esta guisa «son muy buenos como medio medicatriz» ${ }^{72}$.

Este criterio parece haber sido revisado después. Por de pronto Monlau ofrece una visión más ponderada. Señala, en efecto, Monlau que «los vinos dulces contienen un principio nutritivo que no se halla en los vinos secos; se detienen más que éstos en el estómago; no estimulan tanto esta viscera; empalagan en cierto modo, y empachan ó quitan el apetito. Los vinos dulces no convienen á los estómagos que digieren con lentitud. Como encierran partes todavía fermentescibles, pueden causar acedías. La embriaguez que provocan va acompañada de indigestiones». Destacan en este apartado los moscateles y malvasías ${ }^{73}$. Grecia, Italia y España son los países donde se cosechan los principales vinos dulces. Abundando más en ello, Monlau sostenía que la glucosa obra como un alimento respiratorio, y necesita, para ser digerido, gastar una parte de las fuerzas del estómago é intestinos. Por esta razón los vinos dulces suelen ser pesados e indigestos ${ }^{74}$. Añade que los «vinos cocidos» se hallan con muy corta diferencia en el mismo caso que los dulces.

En lo atinente a la graduación alcohólica, el médico Arnaldo de Vilanova recomendaba que se prefiriese el vino más «flojo» posible, «que menos puede sufrir mezcla de agua $\rangle^{75}$. Este era el criterio general de la medicina en relación con los vinos ordinarios (dejando a un lado los denominados «mendicamentosos», de Málaga, hechos con quinina, etc.): la preferencia por los vinos ligeros y de poca graduación alcohólica.

La fragancia del vino, su aroma, se consideraba un índice revelador del nivel de excelencia de un vino. Según la Escuela de Salerno la «fragran-

${ }^{72}$ PUSALGAS, I.: Compendio de higiene, $2^{\mathrm{a}}$ ed. correg. y aum., Librería de José Solá, Barcelona, 1839 , pp. 84-85.

${ }^{73}$ FELIPE MONLAU, P.: Elementos de Higiene privada ó arte de conservar la salud del individuo, op. cit., p. 234.

${ }^{74}$ GINÉ Y PARTAGÁS, J.: Curso elemental de higiene privada y pública, Tomo Primero, Higiene Privada, $2^{\mathrm{a}}$ ed., Barcelona, Imprenta de Narciso Ramirez y Compañia, Barcelona, 1871, pp. 221-222.

${ }^{75}$ VILANOVA, A. de: Regimen Sanitatis, c. 1470. Op. cit., pp. 307-308. 
tia», el buen olor, era un requisito de calidad y salubridad del vino ${ }^{76}$. El galeno Vilanova abogaba por el vino de olor suave ${ }^{77}$. Por su parte, Monlau opinaba que los vinos con olor particular o perfume, muy agradables al olfato, suelen ser muy «sápidos, tónicos y reparadores». No, en cambio, los de olor ingrato o repugnante ${ }^{78}$.

El frescor era un requisito sine que non para que un vino fuera conceptuado como bueno y por tanto saludable. Es conveniente recordar que, conforme al criterio de la Escuela de Salerno, para que un vino fuese considerado plausible debería cumplir cinco requisitos, que comienzan por F: «Fortia, Formosa, Fragrantia, Frigida, Frisca» $\rangle^{79}$. Es decir: Fuerte, Fermoso, Fragante, Fresco y Frisco (prisco o añejo). Pues bien, el «regimine sanitatis» de la Scholae Salernitanae consideraba que el vino rancio era perjudicial, por cuanto «reseca y quema», y además fomenta la bilis y ocasiona estreñimiento. Pero apuntaba una posible solución para remediar este problema: añadiéndole una dosis moderada de auga se convertía en saludable ${ }^{80}$.

El higienismo decimonónico consideraba relevante la temperatura del vino por sus efectos sobre la salud: el vino caliente, bien solo, bien con azúcar, y más o menos cargado de sustancias aromáticas, resultaba: «más excitante y peligroso que el vino á la temperatura natural $»^{81}$. Señalaba Monlau que en los países septentrionales estaba mucho más generalizado que en España el uso del vino caliente, a veces con azúcar y en ocasiones también con especias ${ }^{82}$. Habría que matizar que en España también se

${ }^{76}$ CII.-Vini Probatio. Scholae Salernitanae: De regimine sanitatis (Anglorum Regi scribit Schola Salerni). Cito por la edición de Pedro Felipe Monlau: op. cit., p. 633.

${ }^{77}$ VILANOVA, A. de: Regimen Sanitatis, c. 1470. Op. cit., p. 308

${ }^{78}$ FELIPE MONLAU, P.: Elementos de Higiene privada ó arte de conservar la salud del individuo, op. cit., p. 234.

${ }^{79}$ Esto fundamentalmente, pero aún se contemplaban otros aspectos complementarios: limpio, posado, sutil, maduro, bien diluido, espumoso y que se cuele con moderación. CII.-Vini Probatio. Scholae Salernitanae: De regimine sanitatis (Anglorum Regi scribit Schola Salerni). Cito por la edición de Pedro Felipe Monlau: op. cit., p. 633.

${ }^{80}$ CVI.-Vinum Vetus. Scholae Salernitanae: De regimine sanitatis (Anglorum Regi scribit Schola Salerni). Cito por la edición de Pedro Felipe Monlau: op. cit., p. 634.

${ }^{81}$ FELIPE MONLAU, P.: Elementos de Higiene privada ó arte de conservar la salud del individuo, op. cit., p. 236.

${ }^{82}$ FELIPE MONLAU, P.: Elementos de Higiene privada ó arte de conservar la salud del individuo, op. cit., pp. 236-237.

«CUADERNOS DE ESTUDIOS GALLEGOS», Tomo XLIX, Fascículo 115, Santiago 2002. 
empleaba con bastante profusión el vino caliente, con o sin azúcar o miel. Era un remedio popular del que se solía echar mano en el invierno. Por lo tanto, la mentalidad popular no tenía la misma prevención que la que mostraba el eminente higienista.

La preocupación por la salubridad del vino se hacía extensiva también al caso de que el vino pudiese estar provisto de gas carbónico. Los vinos espumosos, como el champagne (Champaña), le parecían a Monlau muy estimulantes, propiedad en mucha parte debida, según su parecer, a la acción del gas carbónico ${ }^{83}$. Parece inferirse que la estimulación se refiere a la digestión, lo que el higienista suele contemplar positivamente.

Por su parte, Juan Giné y Partagás sostenía un criterio coincidente: el gas carbónico eestimula la mucosa del estómago y activa la digestión. Añade además, que dicho elemento pasa a la sangre, aumentando su fluidez, e incita poderosamente los centros nerviosos. Pero no dejaba de advertir que su uso continuado podía ocasionar temblor ${ }^{84}$.

Por otra parte, médicos e higienistas consignaban un repertorio de factores y circunstancias que influían en la condición saludable del vino, pero que no dependían de sus cualidades inherentes.

Jugaba un papel la estación del año, según fuese invierno o verano. El médico catalán Arnaldo de Vilanova recomendaba a comienzos del siglo XIV que el vino que habría de tomarse en el verano debería ser blanco o clarete y en el invierno «tinto o bermejo» ${ }^{85}$.

Parecía fundamental la hora del día en que se tomara el vino y en especial si se hacía en ayunas o bien como acompañamiento de algún alimento.

La medicina del siglo XIX sostenía que los efectos del vino sobre la salud no eran iguales si se ingería a unas horas u otras. El vino tomado en ayunas parecía a los higienistas infinitamente más peligroso y perjudicial

${ }^{83}$ FELIPE MONLAU, P.: Elementos de Higiene privada ó arte de conservar la salud del individuo, op. cit., p. 236.

${ }^{84}$ GINÉ Y PARTAGÁS, J.: Curso elemental de higiene privada y pública, Tomo Primero, Higiene Privada, $2^{\mathrm{a}}$ ed., Barcelona, Imprenta de Narciso Ramirez y Compañia, Barcelona, 1871, pp. 221-222.

${ }^{85}$ VILANOVA, A. de: Regimen Sanitatis, c. 1470. Op. cit., pp. 307-308. 
que bebido a las horas de comer $^{86}$. Sostenía, en efecto, Monlau que con las comidas $\mathrm{y}$, siempre en dosis moderadas, las bebidas fermentadas resultan positivas para el organismo, pues excitan el estómago, aumentando sus secreciones y activando en él la circulación. En síntesis: «ayudan y aceleran la digestión ${ }^{87}$. En cambio, fuera de las horas de comer, al estar el estómago desocupado, producen un efecto todavía más estimulante, de todo punto inútil, y por lo mismo «altamente perjudicial».

En este mismo sentido, un estudio de Gustavo Garrido recoge la creencia popular en la conveniencia de evitar la ingesta de vino con el estómago vacío ${ }^{88}$. Se constata también en la practica tradicional del consumo del vino por parte de la gente del pueblo que cuando se tomaba fuera de las comidas, se procuraba hacer lo posible para acompañarlo bien fuera con un trozo de pan o bien con alguna otra cosa de picar (lo que se denomina un pincho o tapa).

La Medicina tomaba también en consideración las características e idiosincrasia del bebedor para juzgar qué tipo de vino y en que dosis resultaría aconsejable para su salud. Para ello tenía muy en cuenta el temperamento de la persona.

La fisiología medieval estimaba que el cuerpo contenía cuatro fluidos o humores que determinaban el temperamento de cada hombre, según su relativo predominio. Reparaba además en que los órganos que segregaban tales humores se hallaban sometidos al influjo de los planetas, motivo por el cual el carácter del hombre estaba escrito en sus astros ${ }^{89}$.

Esta visión persistió en las centurias posteriores. Así, en el siglo XVII se contemplaban cuatro temperamentos humanos, cuatro «humores» que se alojan en el cuerpo del hombre ${ }^{90}$ : la flema (o pituita), la sangre, la bilis (cólera) y la melancolía (bilis negra) que hallaban su precisa correspon-

${ }^{86}$ FELIPE MONLAU, P.: Elementos de Higiene privada ó arte de conservar la salud del individuo, op. cit., p. 237.

${ }^{87}$ FELIPE MONLAU, P.: Elementos de Higiene privada ó arte de conservar la salud del individuo, op. cit., pp. 228-229.

${ }^{88}$ GARRIDO, G.: «Alimentación e enfermedade: $\mathrm{O}$ viño e as uvas», Ingenium. Cadernos de Historia das Ciencias e das Tecnicas. Publicación do Seminario de Estudos Galegos, núm. 6, 1999, p. 135.

${ }^{89}$ HALL, J.: «Cuarro temperamentos», Diccionario de temas simbólicos y artísticos, Alianza, Madrid, 1987, p. 103.

${ }^{90}$ Le Thrésor de santé ou Mesnage de la vie humain, Lyon, 1607, pp. 61-63.

«CUADERNOS DE ESTUDIOS GALLEGOS», Tomo XLIX, Fascículo 115, Santiago 2002. 
dencia en los cuatro elementos constitutivos del universo, a tenor de la tradición griega: el agua, el aire, el fuego y la tierra. De este modo, la preponderancia de uno $\mathrm{u}$ otro «humor» determinaba un temperamento flemático, sanguíneo, colérico o melancólico.

Pues bien, en opinión de Flandrin ${ }^{91}$, esta cuadruple división de los temperamentos humanos había que ponerla en correlación con las cuatro grandes categorías de vinos: blancos, negros, tintos y claretes, que se diferenciaban no solo por su color sino también por su naturaleza física y sus diferentes propiedades medicinales ${ }^{92}$, oponiéndose el blanco y el negro por todos los conceptos ${ }^{93}$.

En efecto, el vino blanco, pese a su mayor graduación alcohólica, se conceptuaba como de tenue sustancia y «poco caluroso»" ${ }^{94}$. En tanto que elemento «ligero» representaba el aire. En la medida en que es inmaterial, el vino blanco consigue disolver los humores crasos que embarrassent el organismo y poseé una virtud «aperitiva», en el sentido etimológico latino de «aperire», abrir una via, y acelera la digestión y las excreciones. El alcohol, que se denomina «espíritu del vino», lo poseé en mayor medida el blanco; esto es lo que hace que el blanco se suba a la cabeza, enturbie la vista y «réjouit les esprits». Como contraposición, el vino negro sería la tierra ${ }^{95}$. Colmado de materia cenagosa, el vino negro, confiere pesantez a la persona, causa obstrucciones y deposita materias inasimilables que entorpecen la digestión.

Ahora bien, la correspondencia era de naturaleza compleja puesto que influía diversa suerte de factores y contingencias experienciales que aparecían entreverados.

En la versión ofrecida por el paradigma de la medicina del siglo XIX, se mencionaban tres «temperamentos» primordiales, apellidados a veces

${ }^{91}$ FLANDRIN, J.L.: Chronique de Platine. Pour une gastronomie historique, Editions Odile Jacob, Paris, 1992, p. 258.

${ }^{92}$ Le Thrésor de santé ou Mesnage de la vie humain, Lyon, 1607, pp. 61-63.

${ }^{93}$ FLANDRIN, J.L.: "Vins d'hier: Fonctions et usages sociaux», La vigne et le vin, La Manufacture, Lyon \& Cité des Sciences et de l'Industrie de la Villette, Paris, septembre 1988, p. 297.

${ }^{94}$ FLANDRIN, J.L.: Chronique de Platine, op. cit., p. 260.

${ }^{95}$ FLANDRIN, J.L.: Chronique de Platine, op. cit., pp. 259-260. 
de manera más positivista como «tejidos»» ${ }^{96}$ : el vascular, el nervioso y el muscular. Pero como quiera que el sistema vascular se subdividía en sanguíneo y linfático, resultaban en último análisis cuatro temperamentos simples: sanguíneo, linfático, nervioso y muscular.

Ahora bien, la teoría se completaba con el concepto de temperamento parcial, que proviene del predominio de alguno de los mencionados tejidos cardinales en algún órgano visceral de primera importancia, o en alguna determinada región del cuerpo. Y también se complicaba habida cuenta de que se consideraba raro que fuese uno solo el sistema predominante, por lo que el temperamento simple pocas veces se daba. Por lo regular preponderaban en un mismo individuo dos o más sistemas sobre los demás, dando lugar a un temperamento mixto ${ }^{97}$.

Otros médicos tendían a emplear un enfoque más simplificado. En la obra de Antonio Surós, «Lecciones de higiene y economía doméstica» ${ }^{98}$, cuya parte higiénica fue revisada por «distinguidos médicos» y logró la aprobación oficial del gobierno como texto para las escuelas en 1880, y recibió a la postre un premio pedagógico, se aceptaba la teoría de los tres sistemas nerviosos: nevioso, sanguíneo y linfático. Según la cual, el temperamento de una persona depende del predominio de uno de ellos: en el nervioso prevalece la irritabilidad de los nervios; en el sanguineo, impera el humor de la sangre, en tanto que en el linfático es hegemónica la linfa y las materias grasas. Teniendo presente esta división, convenía administrar a cada cual un régimen dietético particular y unas bebidas diferentes.

Esta triple partición simplificada la encontramos también en un manual de divulgación higiénica, del año $1909^{99}$, de la autoría de dos maestros pertenecientes a la escuela pública de Barcelona, Juan Ruíz y $\mathrm{M}^{\mathrm{a}} \mathrm{de}$ los Ángeles Muncunill: Breves nociones de higiene y fisiología humana.

Vayamos con las recomendaciones alcohólicas apropiadas para cada uno de estos «tipos» humanos.

${ }^{96}$ GINÉ Y PARTAGÁS, J.: Curso elemental de higiene privada y pública, op. cit., pp. 299-300.

${ }^{97}$ GINÉ Y PARTAGÁS, J.: Curso elemental de higiene privada y pública, op. cit., p. 300 .

${ }^{98}$ SURÓS, A.: Lecciones de higiene y economía doméstica, op. cit., p. 38 y nota 1 .

${ }^{99}$ RUÍZ, J.; MUNCUNILL, M.A.: Breves nociones de higiene y fisiología humana, Ruíz y Felíu, $3^{\text {a }}$ ed. Barcelona, 1909, p. 15. 
El médico catalán Arnaldo de Vilanova apuntaba a comienzos del siglo XIV que: «Para los cuerpos templados sanguíneos y coléricos, mejor les es beber el vino débil de su naturaleza, echando en él un poco de agua, que vino fuerte con mucha» ${ }^{100}$.

A comienzos del siglo XVII, Le Thrésor de santé ${ }^{101}$ sostenía que los vinos blancos, por aportar escaso calor y nutrimiento, resultaban saludables para las personas sanguíneas, al desobstaculizar sus canales sanguíneos obstruídos por la bilis, y coléricas o por demás ardientes (chauds) puesto que esta clase de vino no engendraba mucha sangre ${ }^{102}$. Y además, estos «temperamentos» deberían abstenerse de tomar vinos rojos o negros limitándose todo lo más a catar algún caldo de suave tintura aleonada (fauve) o rojiza (rougeâtre) ${ }^{103}$.

El doctor Monlau, se refiere a esta cuestión pero combinándola con otros factores complementarios: la edad, la actividad y la estación del año. Sostenía que el vino, y las restantes bebidas alcohólicas fermentadas, pueden ser útiles en parca dosis, de igual modo que lo son los condimentos estimulantes, para los linfáticos, los de estómago perezoso, los viejos, los que ejercitan mucho sus fuerzas físicas, en tiempo de invierno o por el contrario en época de calores muy extraordinarios y enervantes, $o$ bien cuando se han ingerido alimentos muy refractarios a la acción gástrica, etc. En cambio, resutarán muy perjudiciales para los biliosos y sanguíneos, como también para los jóvenes de estómago robusto, o a quienes lleven una vida sedentaria, o en la primavera, etc ${ }^{104}$. Sostenía además que a las personas nerviosas convenía mejor el vino tinto en razón de resultar menos excitante que el blanco ${ }^{105}$.

En opinión del higienista Giné y Partagás, difundida en la segunda parte del siglo XIX, los temperamentos «sanguíneos» debían servirse de

${ }^{100}$ VILANOVA, A. de: Regimen Sanitatis, c. 1470. Op. cit., p. 308.

${ }^{101}$ Le Thrésor de santé ou Mesnage de la vie humain, Lyon, 1607, pp. 61-63.

${ }^{102}$ FLANDRIN, J.L.: Chronique de Platine, op. cit., p. 260.

${ }^{103}$ Le Thrésor de santé ou Mesnage de la vie humain, Lyon, 1607, pp. 61-63.

${ }^{104}$ FELIPE MONLAU, P.: Elementos de Higiene privada ó arte de conservar la salud del individuo, op. cit., pp. 229-230.

${ }^{105}$ FELIPE MONLAU, P.: Elementos de Higiene privada ó arte de conservar la salud del individuo, op. cit., p. 233.

«CUADERNOS DE ESTUDIOS GALLEGOS», Tomo XLIX, Fascículo 115, Santiago 2002. 
las bebidas alcohólicas con suma moderación ${ }^{106}$. En cambio, a los «linfáticos» las bebidas alcohólicas y las amargas les convenían para activar el lánguido movimiento de la sangre. Los «nerviosos» podían favorecer su digestión recurriendo al vino puro en corta cantidad. Por lo que hace al temperamento «muscular»o "atlético» se recomendaba el agua y las bebidas acídulas para templar el vigor excedente de sus carnes.

Por lo demás, reparaban también los médicos en la edad del bebedor, el sexo e incluso su actividad laboral: si esta era de índole manual y requería un esfuerzo físico importante o bien se trataba de una actividad sedentaria.

Flandrin ha apuntado que antaño era muy común en Francia atribuir la grossièreté a los vinos tintos (y negros) y la délicatesse a los blancos y claretes ${ }^{107}$. Esta conceptualización tenía desde luego implicaciones médicas pero se hacían extensivas además al terreno de las opiniones gastronómicas y de las consideraciones referidas al estatus social.

Se reputaban los vinos blancos como refinados y delicados. Así, Olivier de Serres, los calificaba en su Théatre d'agriculture ${ }^{108}$ como «délicats et savoureux», «excellents», «exquis», y «précieux». Pués bien, en el siglo XVII, en Francia, los vinos delicados eran conceptuados como idóneos para aquellos que vivían delicadamente. En efecto, Le Thrésor de santé sostenía que los vinos blancos y claretes resultaban adecuados «par les gens de repos» ${ }^{109}$.

Esta sensibilidad parece resultar cercana a la de Álvaro Cunqueiro, quien confesaba su particular devoción por la Treixadura a la que atribuía determinadas virtualidades intelectuales y espirituales: «Yo gusto de los blancos que llevan más de una mitad.de treixadura: son los vinos para aperitivo de estudiosos, del Padre Feijóo o del maestro Otero Pedrayo, y

${ }^{106}$ GINÉ Y PARTAGÁS, J.: Curso elemental de higiene privada y pública, op. cit., p. 305 .

${ }^{107}$ FLANDRIN, J.L.: «Vins d'hier: Fonctions et usages sociaux», La vigne et le vin, La Manufacture, Lyon \& Cité des Sciences et de l'Industrie de la Villette, Paris, septembre 1988 , p. 298.

${ }^{108}$ SERRES, O. de: Théatre d'agricultur et Mesnage des champs, Paris, 1600, Livre Troisième, chap. VIII.

${ }^{109}$ Le Thrésor de santé ou Mesnage de la vie humain, Lyon, 1607, pp. 61-63.

«CUADERNOS DE ESTUDIOS GALLEGOS», Tomo XLIX, Fascículo 115, Santiago 2002. 
al caer la tarde, preparan el alma para la contemplación de las brillantes estrellas» ${ }^{110}$.

No parece que fuese infrecuente en España que las personas dedicadas a los menesteres intelectuales tuviesen debilidad por el vino blanco de baja graduación. Un ejemplo lo constituye Santiago Ramón y Cajal, el premio Nobel español, quien ya de anciano pero activo intelectualmente todavía, se inclinaba por los caldos blancos: «En cuanto al vino, bebo medio vaso pequeño de un vinillo blanco, imitación del Sauternes y casi exento de alcohol» ${ }^{111}$.

\section{EL VINO COMO AGENTE TERAPÉUTICO BAJO EL PRIS- MA DE LA MEDICINA OFICIAL}

Atribuir al vino propiedades no solo salutíferas sino además terapéuticas, parece formar parte del paradigma cultural occidental ya desde los tiempos bíblicos, en la medida en que en la simbología tradicional el vino y la uva representan la sangre de Cristo. Mariño Ferro reproduce un expresivo ensalmo en el que se citan las siguientes y clarificadoras palabras de Jesucristo:

$$
\begin{aligned}
& \text { "Toma mi pan para que comas } \\
& \text { mi sangre para que bebas; } \\
& \text { con esto, hermano mío } \\
& \text { ya te puedes hallar bueno» }{ }^{112} \text {. }
\end{aligned}
$$

Carson I. A. Ritchie nos recuerda en su libro «Comida y civilización» ${ }^{113}$ la figura del buen samaritano que curó las heridas de un maltrecho viajero con vino y aceite, del mismo modo que siguen haciendo hoy en día los

\footnotetext{
${ }^{110}$ CUNQUEIRO, A.: A cociña galega, Galaxia, $3^{\text {a }}$ ed., Vigo, 1980, p. 158.

${ }^{11}$ RAMÓN Y CAJAL, S.: El mundo visto a los ochenta años, Espasa Calpe (Austral Summa), Madrid, 2000, p. 820.

${ }^{112}$ MARIÑO FERRO, X.R.: La medicina popular interpretada, E.X.G., Vigo, 1985, p.112.

${ }^{113}$ CARSON I.; RITCHIE, A.: Comida y civilización, Alianza Editorial, Madrid, 1986 , p. 85 .
}

«CUADERNOS DE ESTUDIOS GALLEGOS», Tomo XLIX, Fascículo 115, Santiago 2002. 
italianos y españoles -dice él-. También San Pablo invitó a Timoteo a beber un trago de vino para aliviar su dolor de estómago.

Eran, por consiguiente, abundantes las referencias que se podían tomar de las Sagradas Escrituras para que quedara bien afincada y fundamentada esta teoría. Basándose en ellas, en los tiempos medievales primordialmente, pero también en épocas más proximas, se le atribuyó al vino propiedades medicinales.

Para el período medieval y los dos siglos posteriores contamos con un haz de trabajos entre los que cabe destacar el estudio de Juan Cruz Cruz ${ }^{114}$, que puede servir como conveniente libro de bitácora para la navegación por las procelosas aguas, surcadas por diferentes corrientes, de la dietética y terapética de la época. Estos estudios ponen en evidencia que los diversos Regimina sanitatis editados en el medievo y el Renacimiento, de tradición hipocrática o galénicas, contemplan un mismo enfoque terapéutico del vino. Y así ha venido sucediendo después.

En efecto, la medicina oficial, no solo la popular, consideró antaño el vino como un recurso terapéutico. Tomemos un ejemplo, aportado por Delfín García Guerra, que puede expresar el criterio sostenido por la clase médica del Antiguo Régimen: en el capítulo de gastos del Hospital compostelano, al promediar el siglo dieciocho, sobresalía «el vino que se consume anualmente en las raziones de enfermos y Ministros, curación de unos y otros», que rondaba los 20.000 reales de vellón anuales, superando netamente los apartados de cereales e incluso el de la carne $^{115}$. En 1733-34 cada paciente recibía una ración diaria de 183,76 mililitros. Esta dosis de alcohol (sumada a la de aguardiente, y tal vez un poco de anís) representaba 109,30 calorías, que suponían el 4,67\% de las calorías totales ${ }^{116}$. Por lo demás, la utilización de vino en los hospitales europeos parece haber sido una practica habitual, como lo pone de manifiesto Andrés Laguna haciendo referencia a los siglos XVI y posteriores ${ }^{117}$.

${ }^{114}$ CRUZ CRUZ, J.: Dietética medieval, La Val de Onsera, Huesca, 1997, pp. 30-34.

115 GARCÍA GUERRA, D.: El Hospital Real de Santiago (1499-1804), Fundación Barrié, Ed. Atlántico, La Coruña, 1983, p. 447.

${ }^{116}$ Estimaciones realizadas por Antonio Eiras Roel y Enríquez Morales; cit. por Delfín García Guerra, op. cit., pp. 174-175.

${ }^{117}$ Así sucedía, por ejemplo en Italia, donde a veces para economizar lo mezclaban con auga. Cfr. Andrés Laguna: Viaje de Turquía, cit. por Delfín García Guerra: op. cit., pp. 173 y 232 .

«CUADERNOS DE ESTUDIOS GALLEGOS», Tomo XLIX, Fascículo 115, Santiago 2002. 
Escogeremos un testimonio producido en la ciudad de Pontevedra, en la década de 1920, que nos muestra que en la dieta de los enfermos se solían incluir «vinos muy puros y de poca graduación»» ${ }^{118}$.

Conviene corroborar las prescripciones teóricas del protomedicato con la praxis, es decir, el protocolo habitual de los médicos corrientes. Es posible verificar que no eran únicamente los tratados de higiene, terapéutica, medicina clínica y bromatología. Los médicos de a pie administraban la dulce medicina no pocas veces con criterio liberal. Son abundantes los testimonios referidos a médicos que recetaban a los enfermos una cierta ingesta vínica. Por lo demás, la publicación «O Tio Marcos d'a Portela» refería unha anécdota que merece la pena reproducir: en la ciudad de A Coruña un grupo de personas se encontraron con un paisano, en 1837, y como lo hallaron cansado y con el semblante demudado, pensaron que tal vez hubiese caminado mucho y que por eso llegaba sudando -en realidad si situación se debía a una pequeña estafa que había padecido-; en base a tal suposición, con vistas a que se recobrase, le hicieron una recomendación que dice mucho acerca de lo que solían recetar los doctores: «Tome, tome, buen hombre / tome, tome, eche un trago /que este le es de aquella clase / que le llaman del Condado, / y a cualquiera que enferme / mandan los médicos dárselo» ${ }^{119}$.

Señalaremos a continuación algunas de las propiedades terapéuticas que se le atribuían al vino.

Antonio Surós señalaba en sus «Lecciones de higiene y economía doméstica», publicadas en 1892, que el vino: «En pequeñas dosis favorece la digestión y estimula el apetito, y por esta razón se preceptúa á las personas débiles de estómago y degestión tardía, y á los ancianos» ${ }^{120}$. Pasado el equinoccio del siglo XIX, el higienista Felipe Monlau, aunque se mostraba cauto con respecto a las bebidas excitantes y fementadas, no dejaba de reconocer que podían servir para «remediar la languidez del estómago» ${ }^{121}$.

${ }^{118}$ SAZ Y ÁLVAREZ, F.R.: Apuntes de economía doméstica para uso de las Escuelas Normales, op. cit., p. 234.

119 «O Preiteante», O Tio Marcos d'a Portela. Parrafeos c'o pobo gallego, Ano sesto. Parrafeo décimo. Ourense, 6 de Xaneiro de 1884, p. 2.

${ }^{120}$ SURÓS, A.: Lecciones de higiene y economía doméstica. Para uso de las maestras de $I^{a}$ enseñanza y madres de familia, op. cit., p. 44.

121 FELIPE MONLAU, P.: Elementos de Higiene privada ó arte de conservar la salud del individuo, op. cit., p. 213. 
Como ya hemos tenido ocasión de mostrar, Monlau admitía el benéfico efecto digestivo que se le suponía al vino ${ }^{122}$.

Por lo demás, el «Tratado popular de medicina», del Doctor Saimbraum (1935) indicaba que el vino mezclado con otros elementos resultaba recomendable para la «lavativa alimenticia» intestinal ${ }^{123}$.

También se valoraban los efectos diuréticos de algunas clases de vinos o bien astringentes, de otras especies, señaladamente aquellas provistas de notable provisión de tanino.

Ya hemos mencionado la extendida creencia en las propiedades antipútridas o antisépticas del vino en el siglo XIX. También los tratados de terapéutica le atribuían al vino propiedades antisépticas. Una profesora de la Escuela de Magisterio de Pontevedra, reflejaba la extendida opinión, en el año 1929, de que el vino poseía una acción preventiva o curativa en presencia de procesos infecciosos; aunque en verdad tenía para sí que no era tan grande como se solía considerar -matizaba con escrúpulo-, ya que al diluirse en el cuerpo las perdía, y no era recomendable valerse de él en grandes dosis, puesto que en tal caso: «(...) sería tan perjudicial para los microbios como para las células» ${ }^{124}$.

Se mencionaba también la virtualidad de combatir los vómitos que poseían los vinos espumosos. En efecto, apuntaba una autora, que tales vinos, al contener azúcar y ácido carbónico, ejercían una acción antiemética ${ }^{125}$.

El vino ha gozado tradicionalmente de la consideración de ser un reconstituyente excepcional ${ }^{126}$. En el siglo XIX, los médicos de los hospitales, como hacían en el de Santiago de Compostela, emplegaban el vino tinto para contribuir al restablecimiento de los enfermos después de las operaciones ${ }^{127}$. No podemos olvidar tampoco el empleo médico con fines

${ }^{122}$ FELIPE MONLAU, P.: Elementos de Higiene privada ó arte de conservar la salud del individuo, op. cit., pp. 228-229.

${ }^{123}$ DOCTOR SAIMBRAUM: Tratado popular de medicina, op. cit., p. 605.

${ }^{124}$ SAZ Y ÁLVAREZ, F.R.: Apuntes de economía doméstica para uso de las Escuelas Normales, op. cit., p. 186.

${ }^{125}$ SAZ Y ÁLVAREZ, F.R.: Apuntes de economía doméstica para uso de las Escuelas Normales, op. cit., p. 186

${ }^{126}$ CARSON I.; RITCHIE, A.: Comida y civilización, alianza Editorial, Madrid, 1986, p. 85 .

${ }^{127}$ Debo a esta información a la amabilidad del investigador de temas científicos Gustavo Garrido.

«CUADERNOS DE ESTUDIOS GALLEGOS», Tomo XLIX, Fascículo 115, Santiago 2002. 
reconstituyentes, en personas débiles o convalecientes de una enfermedad, de los vinos de alta graduación, tenidos por medicamentosos, quinados, de Málaga, Jérez, etc.

Era común recurrir al vino (o más frecuentemente a una bebida más fuertemente alcohólica, generalmente destilada) para la desinfección de las heridas, o tras el parto como elemento higiénico con el que practicar lavados y evitar infecciones que ocasionaban numerosas defunciones. En efecto, en la fase de sobreparto o puerperio, tras la expulsión de las secundinas, Monlau recomendaba el emplego de vino, con una peculiar función que podría tener algo de desinfectante; decía: «Inmediatamente se limpiarán bien la vulva y las demás partes adyacentes, con una esponja ó con un paño fino y agua tibia simple, ó con añadidura de un poco de vino si las partes se hallan demasiado flojas o relajadas».

También entendía el doctor Monlau que resultaba imprescindible practicar el lavado de los genitales, que en algunos pueblos acostumaban a sutituir por un cocimiento emoliente a base de paños embebidos de clara de huevo o aceite, mantequilla, etc. $\mathrm{O}$ también por lociones con vino zucarado.

No solo el vino parecía un agente curativo para las dolencias de los hombres. También se consideraba adecuado para las de los animales como se puede comprobar en el «Compendio de albeytería» publicado por Fernando Sande y Lago, en 1729. El vino, tanto blanco como tinto, era así un ingrediente infaltable en los antiguos tratados de albeiteria. Tenía en tales obras un valor intrínseco, estimándose su esencia condensada. Se estipulaba, de este modo, que se debería poner a cocer en compañía de otros ingredientes «hasta que la humedad del vino se consuma» ${ }^{128}$. En algunas ocasiones se prescribía su utilización sin sufrir ninguna alteración; por ejemplo, para combatir la gangrena, se debería rociar el preparado: «con el espiritu de vino» ${ }^{129}$.

También conviene consignar la utilización del vino blanco por los antiguos veterinarios para ahogar en él las «cochinillas» y las lombrices, con vistas a ponerlas seguidamente a secar al sol y pulverizarlas despues.

${ }^{128}$ SANDE Y LAGO, F.: Compendio de albeyteria, Edicións do Castro, Sada (A Coruña), 1989, p. 237. ( $1^{\text {a }}$ ed. Madrid, 1729)

${ }^{129}$ SANDE Y LAGO, F.: Compendio de albeytería, op. cit., p. 245. 
Cabe resaltar asismismo el empleo de vino, en lugar del auga, como vehículo para transportar ciertos preparados medicamentosos. Por ejemplo, los que habrían de ser ingeridos principalmente por los caballos ${ }^{130}$. Así, el hígado de buey, pulverizada y quemado, debía ser dado a beber con vino tinto, siguiendo la preceptiva de Plinio ${ }^{131}$.

La ciencia médica de nuestros días no acepta que se pueda caracterizar epistemológicamente al vino como una medicina, como ha venido considerando de algún modo la sociedad campesina, sino como un «alimento bueno y saludable». Los dictámenes médicos aceptan, sin embargo, que puede tener efectos beneficiosos e incluso una cierta virtualidad terapéutica. Empleado con moderación, pues es bien conocida la insistencia de los galenos en que una misma sustancia tanto puede obrar como remedio o como veneno; es una simple cuestión de dosis, de grado, de oportunidad, y de que resulte adecuada a la idiosincrasia del paciente; de «temperamento», como dirían sus colegas de antaño. La prognosis médica advierte que los efectos benéficos del vino solo se obtienen en situaciones de ingesta prudente, ya que de producírse en un grado elevado, se generarían transformaciones en las vías de metabolización del alcohol que anularían las virtualidades positivas del vino, permaneciendo en cambio si las indeseables. En suma, la medicina reciente mantiene una actitud de «prudente vinofilia», que supera otra posición bien distinta inmediatamente anterior más radical y reticente contra el vino, cuando el alcoholismo despertaba mayor alarma social. La medicina, de algún modo parece apostar por el epicureismo de la razón y la morigeración de los placeres.

Los estudios más recientes en el campo de las Ciencias de la Salud le atribuyen al vino una serie de efectos beneficiosos. Seguimos aquí primordialmente a José Serrano Cuadrillo, quien supo compendiar con ajustada capacidad de síntesis los principales ${ }^{132}$.

Una primera propiedad biosaludable del vino es la acción antienvejecimiento. Antes de nada rejuvenece los tejidos: tecnicamente, las sustan-

${ }^{130}$ SANDE Y LAGO, F.: Compendio de albeytería, op. cit., pp. 246-247.

${ }^{131}$ SANDE Y LAGO, F.: Compendio de albeyteria, op. cit., p. 256.

${ }^{132}$ SERRANO CUADRILLO, J.: «El vino: pasado, presente y futuro», en Unha prospección cara ó futuro», en Seminario de Estudos Galegos: Os viños galegos no umbral do novo milenio, Ediciós do Castro, Sada (A Coruña), 1997, pp. 121-122. 
cias vínicas captan los radicales libres oxigenados impidiendo sus efectos negativos ejercidos sobre las membranas celulares por oxidación de sus lípidos. Además, contribuye a incrementar el nivel de vitaminá $E$ en la sangre, que es la molécula con mayores efectos antioxidantes en el organismo. Por cierto que, como consecuencia de lo anterior, se le adjudica un cierto efecto preventivo de la demencia senil y de la temible enfermedad de Alzheimer ${ }^{133}$.

Algo muy importante es el papel que se le atribuye al vino como reductor frente a la tendencia que presentan muchos organismos a la acumulación de lipoproteínas en la sangre. También flexibiliza las paredes de los vasos y capilares sanguíneos. Esto representa una protección cardiovascular, ya que la vasoconstricción y la concentración de lipotroteínas son claros factores de riesgo de las dolencias cardíacas ${ }^{134}$. Estudios recientes insisten en que la ingesta moderada de vino ejerce una función terapéutica en presencia de enfermedades cardíacas y cardiovasculares, previene incluso el infarto y resulta apropiado tras un episodio de este tipo. E incluso no parece mal que se tome algo más que una sola y triste copa.

Como la cuestión cordial no puede menos que resultar cardinal, valdrá la pena que nos remontemos a la década de 1950, en que se pudo constatar epidemiológicamente la diferente incidencia de la mortalidad gerenada por accidentes cardiovasculares entre los países consumidores de vino y los que no lo eran. Esta comparación resultaba muy ventajosa para las sociedades situadas bajo la égida de Baco, como podía ser Francia, por ser en ellas sensiblemente menor el índice de defunciones por infarto de miocardio. Como quiera que la ingestión de grasas animales era muy similar entre los distintos países resultaba que el elemento primordial de diferenciación en la dieta era el vino (no el alcohol, puesto que los estados considerados -Dinamarca, Alemania, Reino Unido- lo consumían si bien sub altera specie). Esta constación recibió la denominación de «Paradoja Francesa» ${ }^{135}$.

${ }^{133}$ SERRANO CUADRILLO, J.: «El vino: pasado, presente y futuro», en Unha prospección cara ó futuro», en Seminario de Estudos Galegos: Os viños galegos no umbral do novo milenio, op. cit., pp. 121-122.

${ }^{134}$ SERRANO CUADRILLO, J.: «El vino: pasado, presente y futuro», op. cit., pp. 121-122.

${ }^{135}$ SERRANO CUADRILLO, J.: «El vino: pasado, presente y futuro», op. cit., p. 121.

«CUADERNOS DE ESTUDIOS GALLEGOS», Tomo XLIX, Fascículo 115, Santiago 2002. 
Hacia el año 1982, Masquelier, determinó cuales eran las sustancias contenidas en el vino que revestían propiedades cardioprotectoras: los compuestos fenólicos constituyentes de los taninos (catequinas y procianidinas).

Ítem más: se estima que posée efectos antiinflamatorios, bactericidas $\mathrm{y}$ antivíricos ${ }^{136} \mathrm{e}$ incluso también desarrolla una acción protectora frente a determinados tipos de canceres, merced a que contiene una sustancia llamada «Resveratrol», con virtualidad antioxidante y antimutágeno. Viene esto a significar que inhibe la proliferación de células tumorales ${ }^{137}$.

$Y$ una buena nueva para quienes amen el placer a veces contraindicado por la medicocracia: el vino actúa como protector contra las radiaciones solares y las ionizantes ${ }^{138}$.

\section{EL VINO CONSIDERADO COMO AGENTE TERAPÉUTICO POR LA MEDICINA Y LA PRACTICA POPULAR}

Filgueira Valverde glosa el carácter curativo y preventivo que se le atribuía al mosto en la Baja Edad Media. En la cantiga marial 351 aparece una referencia a un vino milagrero que sanó a los enfermos y los hizo «mui sâos seer». El prodigio lo obró la Virgen haciendo que se colmase de vino una cuba que estaba a punto de agotarse en una romería, cosa inadmisible; $y$ en ese momento:

«E os que antes choravan / começaron de ryir e beveron daquel viño / e juraron, sen mentir, que nunca atal beveran; / e os enfermos guarir foron, quantos del beveron / e pois mui sâos seer» ${ }^{139}$.

${ }^{136}$ SERRANO CUADRILLO, J.: «El vino: pasado, presente y futuro», op. cit., pp. 121-122.

${ }^{137}$ SERRANO CUADRILLO, J.: «El vino: pasado, presente y futuro», op. cit., pp. 121-122.

${ }^{138}$ SERRANO CUADRILLO, J.: «El vino: pasado, presente y futuro», op. cit., pp. 121-122.

${ }^{139}$ X. Filgueira Valverde: Estudios sobre lírica medieval, Galaxia, Vigo, 1992, p.141.

«CUADERNOS DE ESTUDIOS GALLEGOS», Tomo XLIX, Fascículo 115, Santiago 2002. 
En el sistema de creencias tradicionales, el vino ha jugado un rol terapéutico indudable desde el más remoto pasado. Es posible constatar esto en los proverbios que tratan sobre cuestiones de medicina e higiene. Precisemos al propio tiempo que estas formulaciones son creaciones populares, que proceden generlamente de la observación directa, pero distan de ser algo quimicamente puro. Muchos de ellos provienen de reglas oídas a médicos de renombre y conectan con los aforismos hipocráticos, las sentencias galénicas y las prescripciones avicénicas ${ }^{140}$. Pues bien, algunos refranes evidencian con nitidez, como decíamos, las propiedades medicinales que el vulgo le atribuía al vino. Existe uno que hace hincapié en los productos biosaludables, en cierto modo en calidad de medicina preventiva, entre los que desde luego se encontraba el vino: «No hay mejor cirujano / Que el buen pan, la buena carne y el buen trago» ${ }^{141}$. Este otro es más específico: «El aceite de las cepas cura muchas enfermedades» ${ }^{142}$. Algunos proverbios castellanos son asimismo muy elocuentes a este respecto: "Vino de Illana (Guadalajara), todo mal me sana» ${ }^{143}$, y también: «Vino de Madrigal (Ávila), me quita todo mal» ${ }^{144}$.

Se propalan por plazas y caminos de la Galicia rural, villega y también periurbana relatos alusivos al efecto sanador del vino, por lo común tinto, como el del siguiente tenor que cualquiera puede escuchar todavía en la actualidad. Una persona de clase media, con aficiones artísticas, residente en Coiro (Cangas), refería un caso reciente, expresivo de la confianza popular en las benéficas virtudes del vino: una señora estaba internada en un hospital en Zurich, en estado de agonía o preagónico; el hijo, valiéndose del ingenio ideó un procedimiento con el que consiguió burlar la estricta vigilancia del personal sanitario, e introdujo en el recinto unha botella de vino «tinta femia», que le fue dando a beber a quepeños sorbos

${ }^{140}$ Vide sobre esto: Antonio Castillo de Lucas: Refranero médico, C.S.I.C, Madrid, 1944, XII

${ }^{141}$ Refraneiro do viño, op. cit., p. 28.

${ }^{142}$ FERRO RUIBAL, X.: Refraneiro galego básico, op. cit., p. 596.

${ }^{143}$ RODRÍGUEZ MARÍN, F.: Más de 21.000 refranes castellanos no contenidos en la copiosa colección del Maestro Gonzalo Correas. Allególos de la tradición oral y de sus lecturas durante más de medio siglo (1871-1926), Tip. de la «Revista de Archivos, Bibliotecas y Museos»; Madrid, 1926, p. 508.

${ }^{144}$ RODRÍGUEZ MARÍN, F.: Más de 21.000 refranes castellanos no contenidos en la copiosa colección del Maestro Gonzalo Correas. op. cit., p. 508.

«CUADERNOS DE ESTUDIOS GALLEGOS», Tomo XLIX, Fascículo 115, Santiago 2002. 
a su madre, sin que esta le hiciera ascos. Al cabo de poco tiempo empezó a reanimarse, revivió en una cierta medida «y aún tiró así meses»» ${ }^{145}$. Por lo demás, Ricardo, el relojero de Goián, en O Rosal, cantaba una expresiva canción popular que daba cuenta de la confianza en las virtualidades terapéuticas del vino: «Es el vino del Rosal, del Rosal; es el vino de Goián,/ de Goián,/ es la cura radical,//radical,/ cura todo mal» ${ }^{146}$.

Alguien tan ilustrado como el Padre Feijóo, y tan obstinadamente empeñado en combatir las milagrerías y supercherías vulgares, acredita beatamente en las propiedades curativas del vino, dándonos idea de hasta que punto estaba arraigada tal creencia en el imaginario colectivo del dieciocho. Así, en sus cartas eruditas y curiosas comenta un caso muy sintomático: «Sé de tres sujetos de mi Religión retirados del umbral de la muerte dándoles a beber bastante porción de vino, por el cual durante toda la dolencia habían suspirado $»^{147}$. La cuestión nos recuerda una chanza que gustaba contar en sus clases el profesor Moreno Báez cando hablaba de unos frailes que ayunaban y se permitían solo tomar vino. Se mantenían de «vitiminas», ironizaba el catedrático.

Se concedía crédito a la fuerza «catártica» del vino: tanto en el plano físico, como agente purificador de los virus o partículas nocivas que pudiese albergar el organismo, o que pudiesen introducirse en él, así como también en el de la psique. De una tal manera lo debió percibir Otero Pedrayo para decidirse a atribuir a Frei Don Veremundo de Rebordechán, prior de los sanjuaistas de Beade en su obra «O desengano do prioiro», la creencia «en la fuerza catártica» ${ }^{148} \mathrm{del}$ vino. Este autor le atribuye incluso al zumo de la vid, por su virtud purificativa y depuratoria, una cierta capacidad de servir de antídoto contra las sustancias o elixires tóxicos. En la obra teatral antes citada cobra vida un personaje, el Rei Don Sancho, del que nos dice que era: «El de la manzana emponzoñada, según las

\footnotetext{
${ }^{145}$ Entrevista realizada por Xavier Castro a Camilo Camaño Xestido. Nado en Coiro (Cangas), arredor de 1950 .

${ }^{146}$ Cantiga recollida por Eliseo Alonso: Viños do Rosal e do Condado. Denominación de orixe Rías Baixas, Vigo, 1992, p. 128.

${ }^{147}$ JERÓNIMO FEIJÓO, F.B.: Cartas eruditas y curiosas, T. IV, C. XVII. Cito por la selección de Eduardo Blanco Amor: Antología popular, Ed. Galicia del Centro Gallego, Buenos Aires, 1966, p. 264.

${ }^{148}$ OTERO PEDRAYO, R.: $O$ desengano do prioiro, (1 ${ }^{\mathrm{a}}$ ed. 1952) Galaxia, Vigo, 1998, p. 113.
}

«CUADERNOS DE ESTUDIOS GALLEGOS», Tomo XLIX, Fascículo 115, Santiago 2002. 
Crónicas». Y añade seguidamente que: «Si hubiera zampado un par de tintos despues - ¡bien se ve que no había nacido en el Ribeiro!- hubiera quedado el veneno destituído de su poder» ${ }^{149}$.

Víctor Lis Quibén señala en La medicina popular en Galicia ${ }^{150}$ que para la curación de las enfermedades en general había por toda Galicia «brujos» que hacían una cocción a base de hierbas diversas, vino y también aguardiente. Recoge la receta de un curandero de Santiso (A Coruña), conocido por Pepe do Boi, quien hacía hervir por espacio de varias horas un preparado a base de hierbas: pulitaina, herbamoura, carbueira y rateira. Le añadía miel, grasa de cerdo, mierda de gallina, chofre, canela e higos, aguardiente y cuatro netos de vino. Cuando se había reducido a la tercera parte se dejaba enfriar y se administraba al enfermo este brebaje, trago a trago «hasta que reviente o sane».

Se empleaba el vino en enfermedades de sintomatología diversa, con frecuentes trastornos digestivos y etiología compleja, que oscilaba entre lo psiquíco y lo somático, aspectos ambos frecuentemente interrelacionados en el imaginario popular vinculado con las cuestiones de la salud.

Las lombrices se solían combatir con un preparado vermicida en el que intervenía el aguardiente. Pero también se le atribuían al vino propiedades vermifugas: se expulsaban las lombrices con una infusión de herba lombriguera hecha en vino.

Los curanderos («menciñeiros») tenían que habérselas con dolencias proteicas, caracterizadas por debilidad del organismo, malestar general, o bien por perturbaciones digestivas y a veces también se manifestaban bajo la apariencia de afecciones de la piel. Se denominaba este conjunto de síntomas, trastornos y dolencias con la expresión de «mal del aire», influjo negativo que procede de un astro, emana de un determinado lugar, o bien de una persona o un animal, tanto vivo como muerto ${ }^{151}$. Para remediarlo, en muchas partes de Galicia, se recurría a fórmulas terapéuticas en las que estaba presente el vino, aunque en general no era preciso ingerirlo. Lo que no era óbice para que muchas veces se pusiera énfasis en la calidad del vino, que convenía fuese del Ribeiro. En efecto, tanto Víctor

${ }^{149}$ OTERO PEDRAYO, R.: $O$ desengano do prioiro, op. cit., pp. 114-115.

${ }^{150}$ LIS QUIBÉN, V.: La medicina popular en Galicia, Akal, Madrid, 1980, p. 299.

${ }^{151}$ LIS QUIBÉN, V.: La medicina popular en Galicia, op. cit., p. 31. 
Lis Quibén ${ }^{152}$, como X. R. Mariño Ferro («La medicina popular interpretada»), aluden al procedimiento de curación del «mal del aire» que se aplicaba en Forcarei, donde disciplinaban la parte enferma azotándola en modo leve con tres ramitos de hinojo, mientras recitaban el ensalmo: «Te bendigo, te disciplino / con tres ramitos de hinojo / y vino tinto del Ribeiro. / Por la gracia de Deus...» ${ }^{153}$. La misma exigencia con la procedencia del vino se constata en Bearíz y Lalín. Menos escrupulosos con la calidad del mosto parecían ser en cambio en Padrenda (ayuntamiento de Meaño) y Baiona $^{154}$. Y también en Redondela donde el hisopo vegetal con que salpicaban el vino tinto se confeccionaba con hinojo y una rama de ajo. Por lo común había que dar ligeros golpecitos con estas ramas una vez al día, durante nueve seguidos, antes o bien después de la salida o puesta del sol ${ }^{155}$.

En un plano más específico, el de los resfriados, catarros y gripes, se constata esto mismo: "Al catarro / dale con el jarro» ${ }^{156}$, prescribía un proverbio. El etnólogo Taboada Chivite menciona, por su parte, el empleo del vino para combatir los catarros ${ }^{157}$. El vino con grasa de cerdo servía para hacer frente tanto a los catarros como a los dolores de muelas. Por lo demás, las practicas de tomar vino caliente, o más recios alcoholes vehiculados con leche, han menudeado siempre.

Un testigo que recuerda la terrible epidemia gripal que se declaró en la segunda década del siglo XX, nacido en la localidad de Ares en 1895, subraya que el vino desempeñó un importante papel en el repertorio de recursos populares empleados para combatir el mal. Señalaba este relator que: «El vino es muy buena cosa. En la epidemia del dieciocho se curaba la gente con alcohol. Mi tío vino enfermo y le dio el médico medicina, pero no la tomó y bebió y transpiró mucho, y al día siguiente estaba mejor y el médico le dijo que siguiese con la misma medicina» ${ }^{158}$.

\footnotetext{
${ }^{152}$ LIS QUIBÉN, V.: La medicina popular en Galicia, op. cit., p. 47.

${ }^{153}$ Tomo estos dos datos de X. R. Mariño Ferro: La medicina popular interpretada, op. cit., pp. 129-130.

${ }^{154}$ MARIÑO FERRO, X.R.: La medicina popular interpretada, op. cit., p. 113.

${ }^{155}$ LIS QUIBÉN, V.: La medicina popular en Galicia, op. cit., 1980, p. 47.

${ }^{156}$ Refraneiro do viño, op. cit., p. 42.

${ }^{157}$ TABOADA CHIVITE, X.: Etnografia galega. Cultura espiritual, Galaxia, Vigo, 1972, p. 89.

${ }^{158}$ Entrevista realizada por Fernando García Gonzalez a Eugenio Martínez Rey, nacido en Ares (A Coruña) en el año 1895. Fondo Historga.
} 